\title{
EFFECTIVENESS OF CHILD PROTECTIVE SERVICES INTERVENTIONS AS INDICATED BY RATES OF RECIDIVISM
}

\begin{abstract}
A thesis presented to the faculty of the Graduate School of Western Carolina University in partial fulfillment of the requirements for the degree of Master of Arts in Clinical

Psychology.
\end{abstract}

By

David Travis Solomon

\author{
Director: Kia Asberg \\ Assistant Professor \\ Psychology Department
}

Committee Members: Dr. Alvin Malesky, Psychology

Dr. Christopher Cooper, Political Science and Public Affairs

May 2012 


\section{ACKNOWLEDGEMENTS}

First and foremost I would like to thank Child Protective Services of Haywood County for allowing me access to their facilities and their case files. Without this opportunity, this project would not have been possible. I know that time is scarce, and I am grateful for all the workers taking their time to help me with my thesis.

I would also like to thank my committee for all of their support in developing and completing this project. Dr. Alvin Malesky’s knowledge of legal and policy issues helped to shape the direction of my research, guided my search for relevant references, and informed my conclusions. Without Dr. Christopher Cooper's awareness of statistical procedures, specifically logistic regressions, which are relatively uncommon in psychological research but more widely used in his field, I would have drowned myself in an overwhelming number of t-tests and chi squares. Finally, Dr. Kia Asberg assisted me not only with my design, but also nurtured the development of my writing abilities, which has been invaluable and will continue to be an integral skill in my academic and professional future. Additionally, she was there with a parsimonious sensibility, which helped me to edit my design to something that was feasible but still rewarding. Finally, and perhaps most importantly, she kept me sane over the past year of spending long hours scrutinizing documents in the CPS archives.

Lastly, I want to thank my colleagues Valerie Russell and Stephanie Pantschyschak, who provided company in the file room and without whom I would have had to spend even more time bent over the records; I cannot say how much I appreciate their help with data collection. 


\section{TABLE OF CONTENTS}

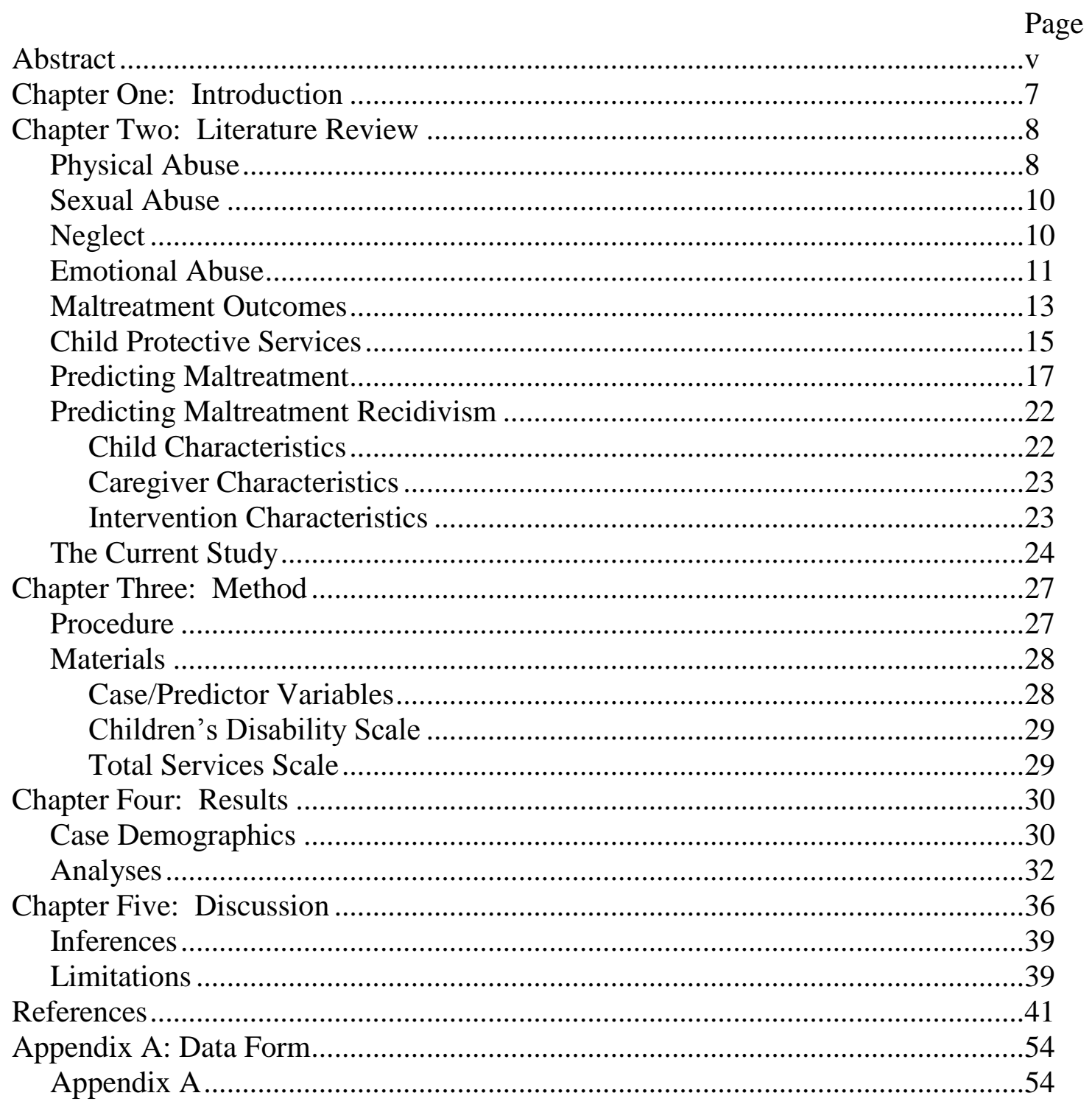




\section{List of Tables}

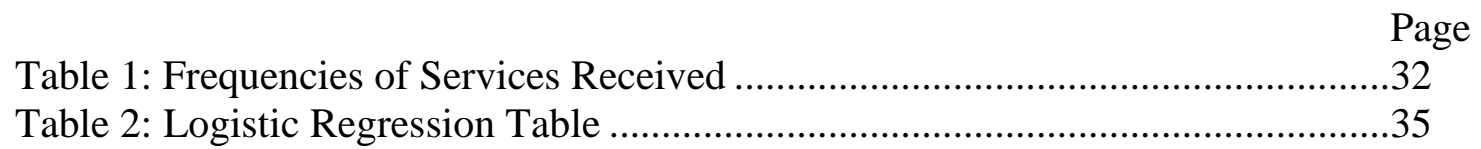




\title{
ABSTRACT \\ EFFECTIVENESS OF CHILD PROTECTIVE SERVICES INTERVENTIONS AS INDICATED BY RATES OF RECIDIVISM
}

\author{
David Travis Solomon \\ Western Carolina University (March 2012) \\ Director: Dr. Kia Asberg
}

Child maltreatment is a pervasive problem with a number of negative consequences, both in terms of human suffering and economic costs. This issue is compounded by the alarming rates of abuse recidivism (i.e., having a second case of abuse following the original event), which has been linked to even poorer outcomes for children involved. Child Protective Services (CPS) is the government agency charged with intervening in cases of abuse and preventing further maltreatment. While many studies have examined the relationship between background variables and recidivism, fewer studies have examined CPS interventions in this regard. A better understanding of these factors could help inform CPS on which interventions to employ, or which cases may require closer monitoring. Thus, the goal of the current study is to test the predictability of recidivism based on both background factors (e.g., disability status of the child and caregiver, age of the child, type of abuse) and CPS interventions (e.g., providing therapy for the caregiver or child, removing the child from the caregiver temporarily). Two predictors, minority status of the caregiver and providing therapy for the caregiver, were associated with reduced recidivism outcomes, while temporarily removing the child from the caregiver was associated with increased chances of recidivism. It may be concluded that cases 
involving child placement away from the caregiver may require further monitoring by CPS, and that ordering therapy for more caregivers may help to reduce recidivism rates. 


\section{INTRODUCTION}

Despite findings that child abuse rates are on the decline (Jones, Finkelhor, \&

Halter, 2006; McCarroll, Fan, Newby, \& Ursano, 2008), childhood maltreatment is still a pressing problem, both in the United States and internationally (Svevo-Cianci, Hart, \& Rubinson, 2010). In the year 2009, over 700,000 children in the United States were found to have been victims of some type of maltreatment, including an estimated 1,770 cases resulting in fatalities (U. S. Department of Health and Human Services, 2010). The state of North Carolina specifically saw between 24,500 and 31,100 cases of child maltreatment requiring social services each year from 2002 to 2006 (North Carolina Department of Social Services, 2011).The negative impact of childhood abuse and neglect has been well-documented and empirically validated. Childhood physical abuse, sexual abuse, neglect, and emotional abuse (collectively called "maltreatment") can leave numerous physical and psychological scars affecting the child's adjustment not only at the time of abuse, but also into young adulthood (Bagley \& Mallick, 2000; Southerland, Casanueva \& Ringeisen, 2009) and beyond (Berenbaum, Thompson, Milanak, Bode, \& Bredemeier, 2008; Fassler, Amodeo, Griffin, Clay, \& Ellis, 2005). Thus, child maltreatment is a serious problem, and its prevention, both primary (e.g., before the first report) and secondary (after the first report), is of the utmost importance. 


\section{LITERATURE REVIEW}

There are no standard definitions for the different types of maltreatment, or what types of actions constitute abuse; the definitions vary by author, and even legal terms can vary by state (Children's Bureau, 2009). Runyan and colleagues (2005) found that research definitions of maltreatment often differ from those used by social workers. In some cases, determinations of what constitutes maltreatment are unreliable, even when made by social workers whose task it is to identify and substantiate cases of alleged abuse (Slep \& Heyman, 2002). The following is a set of commonly used definitions for the four classifications of maltreatment: physical abuse, sexual abuse, neglect, and emotional abuse, as well as other situations that do not fit into these categories.

\section{Physical Abuse}

In 2009 , about $17.8 \%$ of substantiated maltreated cases investigated by social services involved some form of physical abuse (U. S. Department of Health and Human Services, 2010). Physical abuse is the intentional infliction of physical injury to the child. Examples of physical abuse include hitting with a fist or other object, shaking, burning, biting, kicking, and even poisoning or holding the child underwater (Slep, \& Heyman, 2002). Some states also include any action performed or omitted by the parent that places the child at risk of physical harm, even if no injury is sustained (Children's Bureau, 2009). For example, the state of North Carolina defines physical abuse as occurring when a caregiver "allows or inflicts serious injury by non-accidental means" (Children's Bureau, 2003b, p. 40). 
Moreover, corporal punishment is a type of discipline that can be defined as "the intentional infliction of physical pain for a perceived misbehavior" (Block, p.183). Although many studies have found a link between corporal punishment and maladaptive outcomes for children, spanking and similar behavior is typically not considered to be abuse in the United States (Hicks-Pass, 2009), unless it is excessive or leaves a mark or other injury (Slep, \& Heyman, 2002). Opponents of corporal punishment (e.g. Bethea,1999) claim that spanking can become more severe, leading to physical abuse. Opponents also point to research linking corporal punishment to aggression in children (Block, 2003), and point out that adults in the United States have legal protection against physical violence (Gil, 1995).

Despite corporal punishment not being considered a type of maltreatment, many parenting skills courses, offered to caregivers accused of maltreatment, focus on reducing physical punishment in favor other methods of punishment. Unfortunately, one study found that that parents who had completed parenting courses had only nominally better parenting outcomes than those who did not complete a course, and corporal punishment behavior remained the same in the treatment group, with no reduction in spanking practices (Casanueva, Martin, Runyan, Barth, \& Bradley, 2008). One qualitative study found that mothers who had been referred to parenting courses because of child physical abuse cited several reasons for continuing to use corporal punishment, including religious convictions (e.g., the Bible says, "spare the rod, spoil the child"), or the belief that many of the alternate punishments they had learned through the parenting classes, such as timeout, were not appropriate for their older children (Bolen, McWey, \& Schlee, 2009). Overall, although corporal punishment is not covered under the definition of 
maltreatment, physical abuse interventions tend to have a bent towards curbing spanking practices.

\section{Sexual Abuse}

A second type of maltreatment is sexual abuse, which can be constituted by nearly any sexual act involving a minor. Sexual abuse can include non-contact acts, such as the perpetrator exposing their body to the child, or having the child expose him or herself, or contact acts, such fondling or sexual assault (Slep, \& Heyman, 2002). Exploitation is also covered in many definitions of sexual abuse, which includes using a child for child prostitution and child pornography (Children's Bureau, 2009). The North Carolina definition of sexual abuse includes "First- or Second degree rape, sexual act or offense [or] preparing pornography" (Children's Bureau, 2003b, p. 40).

Sexual abuse may be of particular concern, as it has been shown to have especially salient, negative outcomes for the child (Fergusson, Boden, \& Hardwood, 2008; Noll, 2008). For instance, Senn and Carey (2010) found that, out of all the maltreatment types, experiences of childhood sexual abuse was the best predictor of risky sexual behavior (e.g., promiscuity and unprotected sex) in adulthood. In 2009, 9.5\% of children involved in substantiated abuse claims had experienced sexual abuse (U. S. Department of Health and Human Services, 2010). Unlike other types of abuse, victims of childhood sexual abuse are predominantly female (Fischer, 1992).

\section{Neglect}

The most common type of abuse is neglect, being experienced within about fourout-of-five substantiated child maltreatment cases (U. S. Department of Health and Human Services, 2010). Beyond that, while physical and sexual abuse rates have seen a 
sharp decline since the early 90 s of up to $36 \%$ and $47 \%$ respectively, neglect saw only a 7\% decline during this same period (Jones, et al., 2006). Neglect is failure to provide the child with basic needs such as food shelter, clothing, and medical needs (Slep, \& Heyman, 2002). Some states also include failing to meet educational needs in their definitions of neglect (Children's Bureau, 2009). According to the state of North Carolina, neglect occurs when a child "does not receive proper care, supervision, or discipline from a [caretaker]; or is abandoned or not provided necessary remedial care; or lives in an environment injurious to welfare; or is placed for care in violation of the law" (Children's Bureau, 2003b, p. 40).

\section{Emotional Abuse}

The final major class of maltreatment is emotional abuse, also known as psychological abuse (Chamberland et al., 2005) or emotional neglect (Prior \& Quinn, 2010). The typical distinction is that "emotional abuse" typically involved caregiver displays of negative emotion, such as name calling, whereas "emotion neglect" signifies a lack of positive emotion being displayed by the caregiver, such as not making the child feel loved (Baker \& Maiorino, 2010). For the purpose of this paper, and indeed many other papers, the term emotional abuse will cover both of these facets. Examples of emotional abuse include belittling the child, such as through name calling (e.g. "You're worthless") threatening the child with physical violence, confining the child, such as locking him or her in a closet (Slep \& Heyman, 2002), and being emotionally distant (Shaffer, Yates \& Egeland, 2009). In North Carolina, emotional abuse occurs when a caregiver "creates serious emotional damage to juvenile evidenced by severe anxiety, depression, withdrawal, or aggressive behavior" (Children's Bureau, 2003b, p. 40). 
Although the U.S. Department of Health and Human Services (2010) reports a prevalence rate of only a little over $7 \%$ of emotional abuse in substantiated maltreatment cases, some researchers believe emotional abuse to be the most common form of maltreatment, but that it is often overlooked because it is harder to detect and often cooccurs with more evident types of maltreatment (Chamberland et al., 2005). Emotional abuse has been linked with aggression, reduced competence, and social withdrawal (Shaffer, Yates, \& Egeland, 2009), as well as other emotional problems such as self-harm and internalizing behavior (Chamberland et al., 2005). Additionally, emotional abuse may also lead to troubled personal relationships. For example, Wekerle and colleagues (2009) found that experiences of childhood emotional abuse were uniquely stronger predictors of involvement in violently abusive dating relationships, both as the victim (this is true for females only) and the abuser (this was true only for males) compared to other predictors involving child characteristics and interventions.

In addition to the above categories, some states also include illicit substance use or production of illicit substances in the presence of the child, giving illicit substances to the child or allowing the child to use illicit substances, and abandonment (leaving the child alone for a prolonged period of time when the whereabouts of the caregiver is unknown) in their definitions of abuse (Children's Bureau, 2009). Overall, child maltreatment - irrespective of the definition used - is associated with a variety of mostly negative outcomes. 


\section{Maltreatment Outcomes}

As noted, childhood maltreatment is associated with many negative consequences. In fact, one study found that nearly half (45.4\%) of young adults in the sample who had experienced childhood maltreatment were at significant risk of developing a mental health problem (Southerland, Casanueva, \& Ringeisen, 2009). Bagley and Mallick (2000) performed a longitudinal study of 290 females, following them from age 3 through 17 , in order to assess the psychological effects of childhood abuse; which, for some of the girls, had occurred as late as age 16. They found that childhood physical abuse and emotional abuse, but not sexual abuse, predicted conduct disorders at age 17, while only sexual abuse and emotional abuse predicted emotional problems (e.g., depression, anxiety and suicidal ideation), even when other background predictors such as poverty and dysfunctional family climate were accounted for.

Childhood maltreatment has also been linked to a greater severity of symptoms in a number of specific psychiatric disorders. For example, one longitudinal study found that young children who had experienced maltreatment were more likely to exhibit psychotic symptoms by age 12 than those who did not experience maltreatment (Arseneault et al., 2011). In one study of psychiatric patients with schizophrenia, those with identified histories of child abuse tended to have a higher number of symptoms, and more severe symptoms (Schenkel, Spaulding, DiLillo, \& Silverstein, 2005). For males especially, experiences of childhood maltreatment have been found to predict the presence of schizotypal personality disorder in adulthood (Berenbaum et al., 2008).

Maltreatment has been linked to other personality disorders as well, especially Cluster B personality disorders (borderline, antisocial, histrionic, and narcissistic 
personality) which are marked by emotional instability (Loper, Mahmoodzadegan \& Warren, 2008). For example, Gratz and colleagues (2008) found that childhood maltreatment predicted borderline personality disorder symptoms above and beyond several other common predictors. Several other studies have likewise found a relationship between childhood maltreatment and borderline personality disorder (e.g. Lobbestael, Arntz \& Bernstein, 2010; Igarashi, et al, 2010; Rogosch, \& Cicchetti, 2005). Maltreatment even seems to affect normal personality traits, especially in predicting higher levels of neuroticism (Nederlof, Van der Ham, Dingemans \& Oei, 2010). Another negative outcome related to child maltreatment is its association with problematic substance use. Young adults who reported maltreatment during childhood and adolescence are more likely to report alcohol and illicit drug use and abuse (Thornberry, Henry, Ireland \& Smith, 2010). Even when controlling for other risk factors such as gender, parental alcoholism, and low parental monitoring, Shin, Edwards and Heeren (2009) found that adolescents who were abused or neglected as children were more likely to engage in binge drinking behavior relative to their non-abused counterparts. It has been suggested that individuals who have been abused and neglected may use alcohol to self-medicate (Trent, Stander, Thomsen \& Merrill, 2007). In fact, using alcohol and drugs to cope with negative affect mediates fully the relationship between trauma symptoms and substance use problems among survivors of childhood sexual abuse (Asberg \& Renk, in press). Also, more severe childhood sexual abuse and problematic substance use predict arrests and incarceration among females (Asberg \& Renk, 2012). 
Unfortunately, a phenomenon known as cycle of violence may also be at play with individuals who have experienced maltreatment in their childhood. Cycle of violence is a term that describes an above average likelihood that those who have been abused will later abuse their own children. About $30 \%$ of abused individuals will likewise maltreat their own children, a much higher prevalence rate than in the general population (Kaufman \& Zigler, 1989). Parents who were maltreated as children are not only more likely to abuse their own children, but are typically more likely to continue to abuse their children even after receiving intervention from the authorities (Hindley et al., 2006; Wood, 1997). The exact mechanism of the cycle of violence is unclear. It is possible that learning and modeling may be involved (Spinetta \& Riger, 1995), or that those who continue the cycle of violence may have inherited genetic predisposition to predictors of abuse (Caspi, 2002).

\section{Child Protective Services}

The issues outlined in the proceeding section emphasize the importance of developing effective strategies, not only to prevent abuse and neglect, but also to reduce the negative effects in individuals who have experienced maltreatment (Thornberry, et al., 2010). The purpose of the Child Protective Services (CPS) division of the Department of Social Services is to protect the well-being of children. Specifically, CPS investigates and intervenes in cases of child abuse and neglect (Connell, Bergeron, Katz, Saunders, \& Tebes, 2007). CPS, in conjunction with the legal system, fulfills this purpose through many types of interventions, such as ordering substance abuse counseling or parenting classes, (U. S. Department of Health and Human Services, 2010), and may include multiple home visitations to monitor the progress and safety of the household after 
referral has occurred (Bethea, 1999). Mental health counseling for both children and caregivers may be ordered, although these services are somewhat rarer (Jonson-Reid, Emery, Drake, \& Stahlschmidt, 2010). CPS may also work with parents to help them receive adequate resources (e.g. medical care, food, housing, and other resources) from other social and welfare agencies (Conley, 2007).

In some cases, it is necessary for CPS to place the child with other caregivers when the home environment is not seen as safe (Barth, Courtney, Berrick, \& Albert, 1994). About one-fifth of children who receive services from CPS are placed, at least temporarily, into foster care (U. S. Department of Health and Human Services, 2010). This is a fairly high prevalence when considering that the 1980 Adoption Assistance and Child Welfare Act, requires that Child Protective Services aim to prevent removal of children from their home if at all possible, and in cases where it is deemed necessary, strive to place the child into permanent placement as quickly as possible (Barth et al., 1994).

Many times the maltreated children are eventually returned to their caregivers, but this is not always the case. Although it is generally seen as a failure of the system, relinquishing of parental rights is sometimes deemed necessary if parents are not making significant progress in an acceptable time-frame, in order to place quickly-developing children in stable homes expediently (Califino, 2003). Additionally, some have criticized CPS's focus on family preservation, claiming that the high rates of recidivism is evidence that children who are returned to their family may, in some cases, be placed in further danger. Also, adoption policies have sometimes been viewed as promoting racial 
segregation, as attempts are typically made to place children with foster homes of similar ethnic make-up to preserve their cultures (Orr, 2003).

\section{Predicting Maltreatment}

In general, when considering possible interventions, it is important to consider the causes or contributing factors of abuse, which are numerous (Bethea, 1999).

When looking at caregiver factors, perhaps that which is most relevant is parental stress-levels. Many parents indicate that stress, and difficulty dealing with stress, was instrumental in their perpetration of abuse, and that stress remained a significant factor in their lives even after CPS involvement (Bolen, McWey, \& Schlee, 2009). Guterman, Lee, Taylor and Rathouz (2009) found that parental stress played the clearest role in predicting child abuse and neglect over other predictors in their study (e.g. personal control and neighborhood factors). Situational stressors, such as having more children in the family, have also been linked to abuse potential (Depanfilis \& Zuravin, 1999). Jouriles and colleagues (2010) go so far as to state that any parenting intervention should aim to also help caregivers deal with their stress in order to be optimally effective.

Also, a higher prevalence of children are abused by their mother or both parents than by fathers alone (U. S. Department of Health and Human Services, 2010), which may relate to additional stressors faced by women. Research has found that younger mothers and less-educated mothers, who are arguably more likely to deal with situational stressors, are more likely to maltreat their children (Boden, Horwood, \& Fergusson, 2007). Additionally, being a single mother has been found to predict maltreatment (Berger, Paxon, \& Waldfogel, 2009). 
Further, having different kinds of support may mediate or alleviate parental stress in cases of child abuse or neglect, thus lessoning the harmful effects of stress. Some examples of support include social support, such as receiving empathy and reassurance from family and friends, and concrete support, such as access to resources like money, food, shelter, and medical care (Counts, Buffington, Chang-Rios, Rasmussen, \& Preacher, 2010). In families where a child is seen as being at risk for maltreatment, having adequate social support for the family reduces the risk that abuse will occur by one-half (Li, Godinet, \& Arnsberger, 2011).

More tangible, concrete support may also be important to family stress levels, since studies have indicated that poverty (which is essentially a lack of concrete resources) has been found to predict child maltreatment and child placement outside of the home (Hearn, 2010). In fact, poverty is one of the most frequently cited risk factor for child maltreatment (Bethea, 1999; National Coalition for Child Protection Reform, 2003).One study on family-preservation (i.e. attempting to prevent future abuse and keep the family intact) found that programs aiming at helping the family obtain concrete support were more effective than programs focusing on parenting and child development (Chaffin, Bonner, \& Hill, 2001). Additionally, some parents involved with DSS have said that their children had been taken from then not for anything that the parent had actively done wrong, but rather based on the fact that they could not afford to provide clothing and other resources for their children, despite wanting to do so (Bolen et al., 2009). With this in mind, it is important for CPS to focus on helping families obtain the resources they need. For example, Bethea (1999) notes, “Until parents' basic needs are met, they may find it difficult to meet the needs of their children" (p. 1583). 
There are other parental issues that may be relevant as well, given that CPS aims to alleviate several other factors that have been linked to childhood maltreatment. One very prevalent problem CPS deals with is parental substance abuse. Parents who abuse substances have a higher incidence of child maltreatment perpetration than parents who do not (Califano, 2003). In fact, substance abuse is a known, significant factor in at least two-thirds of families who are the subject of CPS investigation (Semidei, Radel, \& Nolan, 2001), with some studies finding as high as an $80 \%$ prevalence rate if alcohol abuse is also counted (Young, Gardner, \& Dennis, 1998). Additionally, it has been found that for cases in which substance abuse is a factor, the maltreatment is typically more severe and more likely to require removal of the child from the household (Berger, Slack, Waldfolgel, \& Bruch, 2010). Substance abuse has also been found to predict recidivism in maltreating families (Wolock \& Magura, 1996). Because of this, Barth, Gibbons, and Guo (2006) have called for a focus on empirically based treatments focusing on parental substance abuse to be utilized in child welfare cases. It is important, then, to include parental substance use and abuse as a predictor of child welfare outcomes.

As was previously mentioned, some interventions seek to aid parents increase their parenting skills and knowledge of child development. Child development knowledge includes knowing what is age-appropriate behavior for a child, and may foster more accurate expectations for children (Counts et al., 2010). For example, maltreating parents are more likely to view externalizing behavior more negatively than nonmaltreating parents (Barth, 2009).

Another possible area of interest is how well the family functions as a unit (e.g. having cohesive relationships and conflict resolution). Paavilainen and Åstedt-Kurki 
(2003) found that maltreating families tend to be characterized by chaotic conflicting relationships which may lack caring, which would indicate poor family functioning. Family functioning has been found to be inversely related to occurrences of child maltreatment (Ung, 2009). Specifically, family conflict has been found to be highly correlated with abuse potential, while family cohesion was found to be highly negatively correlated with abuse potential (Mollerstrom, Patchner, \& Milner, 1992). Family functioning may also impact the outcomes for maltreated children, as one study alarmingly found that girls who were victims of childhood emotional abuse and who had a dysfunctional family life were likely to be rape victims as adults (Messman-Moore \& Brown, 2004).

There are many possible factors affecting the outcomes of CPS involvement. These factors may be nonmodifiable, such as type of abuse, race, or gender of the child, or they may be modifiable, such as the type and duration of intervention given or ordered by CPS (Thompson \& Wiley, 2009). In either case, identifying these factors would help inform CPS to plan effective strategies for dealing with cases of child maltreatment, and to recognize instances where additional time and interventions may be warranted (Hindley, Ramchandani, \& Jones, 2006; Kahn \& Schwalbe, 2010).

The effectiveness of CPS involvement can be assessed in a variety of ways, but perhaps the most important outcome measure is the occurrence of recidivism, as repeat cases suggest a failure of the ability of CPS to sufficiently protect children (Bae, Solomon, Gelles, \& White, 2010; Connell et al., 2007), and may indicate that either the family is not getting the adequate services that they need, or that there is a disconnect between the skills learned through CPS intervention and their implementation within the 
family (Children's Bureau, 2003a). It has been found that $30 \%$ of investigated child maltreatment cases involve at least one instance of recidivism within 3 years from the original index event (Connell, et al., 2009), and these rates of re-referral to CPS seem to continue to climb as more time passes, with life-time re-referral rates upwards of $40 \%$ (Connell, et al, 2007; Drake, Jonson-Ried, Way, \& Chung, 2003) or 50\% (English et al., 1999). Although chances for recidivism seem to be highest soon after the index event, and dropping off significantly after 2 years (Hindley et al., 2006). In fact, English and colleagues (1999) found that 50\% of recidivism occurrences take place within 6 months of a case's closing.

Recidivism may be especially important to prevent, not only because it poses a further strain on limited time and resources (Connell et al., 2007), but some studies have shown chronic abuse to have more detrimental effects. According to Graham and colleagues (2010), "Substantial evidence has accumulated documenting the deleterious effects of child maltreatment on later functioning. Indeed, the dimension of chronicity appears to be critical to understanding how maltreatment may lead to psychosocial and behavioral problems and affect child development" (p. 311). They found that chronicity (i.e., occurring multiple instances over time) of the maltreatment predicted later emotional and behavioral problems, especially if it crossed developmental stages. The finding that abuse occurring over several developmental stages more strongly predicts internalizing and externalizing problems has been reproduced in other studies as well (Jaffee \& Maikovich-Fong, 2011). Recurrent maltreatment has also been found to predict other problems, such as delinquency (Lemmon, 2008) and lower IQ scores (Jaffee \& Maikovich-Fong, 2011). 


\section{Predicting Maltreatment Recidivism}

A great deal of research has been done on factors predicting recidivism focusing on child, parent, and situational factors; however, results are sometimes unclear and contradictory (Connell, et al., 2007). This can be seen when considering the relationship of maltreatment type and recidivism. Although the majority of research shows neglect to be the type of maltreatment with the highest recidivism rates (Hindley et al., 2006; Inkelas, \& Halfon, 1997; Jonson-Reid, Drake, Chung, \& Way, 2003; Jonson-Reid, et al., 2010), the results of other studies are less clear. Connell and colleagues (2007) found that neglect cases only had significantly greater likelihood or recidivism compared to sexual abuse, but not emotional abuse, physical abuse, or combined abuse. In another study, both physical abuse and neglect were both significant predictors of maltreatment recidivism. Yet another study found that physical abuse and sexual abuse, but not neglect, predicted recidivism (Thompson \& Wiley, 2008).

Child characteristics. Findings on the relationship of child characteristics to maltreatment recidivism are somewhat more consistent. Studies have typically found that gender of the child is not likely to predict recidivism (Connell et al., 2007; Thompson \&

Wiley, 2008) while age seems to be a factor, with younger children having been found to have higher rates of recidivism (Connell et al., 2007; Connell et al., 2009). In fact, Jonson-Reid and colleagues (2010) found that the probability of recidivism decreases by $3 \%$ for each year older the child is at the first case of maltreatment. Additionally, several studies have found children who have disabilities to be at a higher likelihood for both abuse and recidivism (Connell et al. 2007; Connell et al. 2009). For example, Wood (1997) found that in a sample of Hispanic children, those with disabilities were more 
likely to have a subsequent abuse allegation within the 2-year follow-up. One theory behind this is the greater level of parental stress involved with raising a child who has a disability (American Academy of Pediatrics, 2001).

The relationship of child ethnicity to recidivism is somewhat less clear. One study of over 22,500 youths in the CPS system found that Caucasian children were significantly more likely to suffer a second allegation of maltreatment compared to Hispanic or African-American children (Connell et al., 2007). However, Inkelas and Halfon (1997) found that Caucasian and African-American children were both equally as likely to suffer at least one instances of recidivism, although Caucasian children who were re-abused tended to have more instances of recidivism. It appears, then, that racial and ethnocultural variables warrant further investigation as potential risk factors for recidivism.

Caregiver characteristics. Many parental factors that predict initial abuse of a child are also predictive of maltreatment recidivism (i.e. having a second case of maltreatment after the initial event). Review of child-abuse literature consistently finds measurements of parental stress to be related to abuse recidivism potential (e.g., Inkelas \& Halfon, 1997; McDonald \& Marks, 1991). Parental drug and alcohol abuse history also increases re-referral potential (Connell et al., 2007). One meta-analysis by Hindley and colleagues (2006) found that parents with greater parenting skills tended to have significantly fewer incidences of recidivism. Just as poverty is a strong predictor of abuse, higher financial income seems to be a resiliency factor against maltreatment recidivism (Jonson-Reid et al., 2010).

Intervention characteristics. Although many studies have examined outcomes of CPS and other child welfare interventions, they tend to have small sample sizes and 
have little emphasis on using statistical methods to examine group differences (Maluccio, Ainsworth, \& Thoburn, 2000). Fewer studies have looked specifically at recidivism outcomes, but some findings are available. One study found that in-home services, which focus on crisis intervention and skill building in order to prevent the child being removed from the home, reduced the risk of re-referral to CPS (Jonson-Reid et al., 2010). Longerterm as opposed to crisis focused mental health treatments for either the caregiver or the child has been linked to reduced risk of recidivism (Jonson-Reid et al., 2010), although longer overall duration of CPS involvement has been linked to further abuse (Bae, Solomon, Gelles, \& White, 2010). There are also further indications that reduction in caregiver stress may serve the dual role of increasing caregiver well-being and preventing future abuse. In one study using random group assignment, only 5.9\% of parents receiving a parenting intervention focusing on parental distress in addition to behavioral management skills had a subsequent referral compared to $27.7 \%$ of parents who received service as usual (Jouriles, 2010). While understanding the effects of individual interventions is important, there is also an emphasis by many experts on integrating interventions for the most effective outcomes (Bethea, 1999).

\section{The Current Study}

Child maltreatment is a serious problem that needs to be dealt with effectively. Not only can maltreatment lead to a number of negative outcomes in its victims, ranging from a high prevalence rate of mental health problems and substance abuse, to an increased risk that the child will grow up and become abusers themselves, but it also represents a significant economic impact on social services, healthcare, and the judicial systems in the United States. Although precise economic costs are difficult to obtain, one 
recent review found that estimates for the year 2007 range from $\$ 7$ billion to $\$ 103.7$ billion depending on prediction methods and whether or not human suffering and quality of life are included (Corso \& Fertig, 2010).

It is the task of CPS to defend the well-being of children who have suffered maltreatment by preventing further abuse and neglect, and curbing the negative outcomes that tend to follow in their wake. Much research has been done on background variables predicting recidivism in CPS cases, but considerably less research has been done regarding the effects of specific CPS interventions in preventing recidivism (Antle, Barbee, Christensen, \& Sullivan, 2009). This is alarming, because although the U.S. Advisory Board on Child Abuse and Neglect advocates for intervention strategies at all levels of society (e.g. the individual parents, family, and community), there is little agreement as to which interventions, based on family specific circumstances, should be used to prevent childhood maltreatment (Bethea, 1999).

Current research on maltreatment recidivism is contradictory, unclear, and calls for further analysis (Connell et al., 2007). The purpose of this study is to examine the relationship of background variables (e.g., child, caregiver, family, and abuse characteristics) and CPS intervention variables (e.g., services given, if the child was removed from his or her caregiver, how long the child was in placement, and how often the child changed placement) to predict recidivism rates. The aim is to further clarify the influence of background variables and expand on the research base by incorporating intervention variables, which are under-researched. It is hoped that identifying which variables and interventions predict whether or not recidivism occurs will aid CPS in decision making, as well as improving their intervention practices. It is hypothesized that 
both background variables and CPS intervention variables will be significant predictors of recidivism rates and for parents and children. 


\section{METHOD}

\section{Procedure}

Data was archival, and collected from CPS case files in Haywood county in western North Carolina. Cases were selected with the criterion that they involved at least one instance of substantiated maltreatment; CPS investigations in which the maltreatment was not conclusively established were excluded. Cases were non-randomly selected from a larger sample of case files. Specifically, cases were collected chronologically until the quota (approximately 120 families) of required cases for the study was met. To control for the amount of time that had passed since initial referral, which is a significant predictor of recidivism (English et al., 1999; Hindley et al., 2006), all cases were selected from a pool of cases with an event during the years 2007 and 2008. While most cases originated during those 2 years, some cases had an original index event from prior years. Thus, the first recorded instance of substantiated maltreatment was examined as the index event, and the earliest substantiated event thereafter was used as the recidivism event for analysis purposes. Due to the nature of the archival data, specific cases, each of which typically follows a specific family, were examined rather than individuals. In this way, specific family units could be evaluated. To control for children who were not re-abused due to aging out of the system, cases were not included if the child would turn 18 before the end of time period being assessed (3 years from index).

Files were coded by the primary investigator (PI; $n=68)$ and two secondary investigators (SIs; $n=52$ ). Secondary investigators were trained by the PI prior to coding any files. They first observed the PI's coding procedures and then coded several files 
with the PI. Secondary investigators then coded a file while being observed by the PI before coding several files on their own which were then checked by the PI for accuracy. Several weeks into the study, the PI and SIs coded the same case files independently. Both forms were then compared to insure inter-rater reliability.

\section{Materials}

Case/Predictor Variables. Background variables were collected from the CPS case reports. These variables included demographics of the child, demographics of the parent, family situational factors, and CPS interventions given or ordered. Additionally, the amount of time passed since the initial substantiated referral was recorded. Child characteristics collected included: age of the child at index event, gender of the child, and minority status of the child. Caregiver characteristics included: relationship to child (biological parent, stepparent, other family member, non-family caregiver), gender of caregiver, age of caregiver, and minority status of caregiver. Situational characteristics included: number of children in household, presence of caregiver alcohol abuse, presence of caregiver substance abuse, and type of abuse. The CPS intervention variables collected were: child placed outside of the house (yes/no), where child is placed (other parent, other family member, foster care), length of placement, child returned to parents after placement (yes/no), substance abuse counseling for parent (yes/no), other psychological counseling for parent (yes/no), parenting courses (yes/no), and other concrete support such as housing assistance, or food stamps (yes/no). The number of concrete supports given was also recorded. For the purposes of this study, only new services were considered to be an intervention. For example, if a family was already receiving food stamps or a member was already involved in counseling these would not be counted. 
Additionally, since the focus of this study was on CPS's first responses to maltreatment, interventions initiated over 3 months after the index were not counted as initial interventions.

Children's Disability Scale (CDS). A scale variable was also developed to measure the number of disability-related stressors a household has. Each child in the household could receive 1 point towards this scale for having a mental or emotional disability (such as mental retardation, attention deficit hyperactivity disorder, or suicidality) and 1 point for having a physical disability or chronic health problem (such as deafness, cerebral palsy, or congenital heart defect). Thus, each child could achieve a score from 0 (having no disabilities) to 2 (having at least one physical and at least one mental/emotional disability). Less-serious and easily treatable health problems such as mild asthma and allergies were not coded towards this scale. The final scale consisted of cumulated points across all children in the household.

Total Services Scale (TSS). A final scale was constructed to measure cumulate number of services a family received. A household received 1 point for each service or intervention given or ordered by Social Services. For example, a family that received drug treatment, therapy for their child, and was referred for food stamps would receive a score of 3 on the Total Services Scale.

All data was de-identified and encoded onto a data form before being taken from DSS premises. The data form can be found in Appendix A. 


\section{RESULTS}

\section{Case Demographics}

The 120 cases included 217 children with an average age of 5.8 years $(S D=4.7)$. The sample was fairly homogeneous; only $16.6 \%$ of the sample had a minority status, with $3.7 \%$ being African-American, $8.8 \%$ being Latino, $3.2 \%$ being Native American, and only two subjects being Asian. In the current sample, $47.1 \%$ of the children were female. Forty-one of the children were reported in the files to have a mental or emotional disability ( 25 of which were in a case that included recidivism), whereas only 10 are reported to have a physical disability or chronic health problem (6 of which were in a case that included recidivism).

Furthermore, the sample included 216 caregivers (including 117 in the recidivism group) with an average age of $29.8(S D=9.9)$. According to the case files, 172 of the caregivers were considered to be perpetrators in the maltreatment, with $33.3 \%$ of the sample identifying maltreatment by the primary female caregiver, $25 \%$ of the sample identifying the primary male caregiver as the perpetrator, and the remaining cases being attributed to both caregivers. Within the sample, 183 of the participants were biological parents (90 in the recidivism group), 12 were step-parents ( 9 in the recidivism group), 9 were other relatives ( 5 in the recidivism group), such as a grandparent, and 23 were nonrelated caregivers (16 in the recidivism group), such as a boyfriend or a girlfriend of the parent, or a group-home worker. In $51.7 \%$ of the cases the caregivers were single, divorced, or separated, with the remaining cases involving caregivers who were either married or cohabitating. As with the children of the sample, the caregivers were 
predominantly Caucasian (88.2\%). The next largest group was Latino (7.5\%), followed by African-American (1.9\%), Native American (1.9\%), with Asian (.5\%) being the smallest minority group in the sample. Collapsed across all minority groups, $34.4 \%$ of cases involving a minority caregiver experienced recidivism compared to $56.8 \%$ of white caregivers. Concerning disability status, 60 of the subjects were reported to have a mental or emotional disability, 31 of which were involved in a case with recidivism and 16 were reported to have a physical disability or chronic health problem, 7 of which were involved in a case of recidivism.

The most common type of maltreatment during the index event was neglect, being reported in 109 (90.8\%) of cases. Recidivism occurred in 58 (53.2\%) of neglect cases. The next largest abuse type at index was physical abuse $(22.5 \%)$ followed by sexual abuse $(8.3 \%)$. Recidivism occurred in $44.4 \%$ of physical abuse cases and $30.0 \%$ of sexual abuse cages. Only 4 cases made a specific mention of emotional abuse in the report. Slightly over half $(50.8 \%)$ of the cases involve at least one substantiated case of recidivism following the index event. Domestic violence was mentioned in 52 (43.3\%) of the cases, 29 of which involved recidivism. Furthermore, alcohol abuse was mentioned in $43(35.8 \%)$ of the cases, 25 of which involved recidivism, and abuse of other drugs, such as marijuana, methamphetamine, cocaine, and prescription drugs, was reported in 66 (55\%) cases, 34 of which involved recidivism. The average number of services given by the Department of Social Services and/or Child Protective Services per case was 1.6 $(S D=1.4)$. The most number of services any case received was 5 , which occurred in only $3(2.5 \%)$ cases. In $29.2 \%$ of cases no interventions were mentioned in the case file. Such cases typically involved less severe maltreatment cases in which caregivers signed 
agreements stating that children would always have a sober caregiver, or would always have their medical needs attended to. Alternately, the non-offending caregiver may have agreed to keep the children away from the offending caregiver during the course of the investigation. Table 1.provides frequency counts $(\mathrm{F})$ for specific interventions received across the 120 case files, the percent of total cases (PT) which received the treatment, the frequency of cases in which the treatment was unique to (FU; i.e., the percent of cases for which a the treatment was the only one given), and the percentage of recidivism (PR) in cases involving that treatment.

Table 1. Frequencies of Services Received

\begin{tabular}{l|llll}
\hline Intervention & $F$ & $P T$ & $F U$ & $P R$ \\
\hline Anger Management & 10 & $8.3 \%$ & 0 & $50 \%$ \\
Child Removed & 29 & $24.2 \%$ & 3 & $79.3 \%$ \\
Temp. & & & & \\
Concrete Supports & 31 & $25 \%$ & 6 & $45.2 \%$ \\
Parenting Classes & 27 & $22.5 \%$ & 1 & $44.4 \%$ \\
Substance Abuse & 45 & $37.5 \%$ & 10 & $45.5 \%$ \\
Services & & & & $41.4 \%$ \\
Therapy for Child & 29 & $24.2 \%$ & 9 & $40.0 \%$ \\
Therapy for Parent & 30 & $25 \%$ & 1 &
\end{tabular}

\section{Analyses}

All analyses were performed using individual cases, not people, as the unit of analysis. Initial exploratory analyses were performed to test the isolated relationships between case and family characteristics to maltreatment recidivism. An independent samples t-test found that the Children's Disability Scale score did not differ significantly between the recidivism and the no recidivism group $(M=.51, S D=.70$ and $\mathrm{M}=.34$, $S D=.54$, respectively), $t(133)=-1.48, p=.14$. Since previous research has indicated that younger mothers are more likely to maltreat their children, an additional t-test was performed using only the female participants to assess if age played a factor in abuse 
recidivism as well. Results indicated that the ages of mothers who did not re-abuse their children $(M=29.18, S D=9.45)$ did not differ significantly from those that did re-abuse their children $(M=28.48, S D=8.22), t(112)=0.42 p=.68$. Likewise there was no differences between recidivism and no recidivism groups in terms of the number of children in the family ( $p=0.14$ ) nor was there for the age of the youngest child $(p=.81)$. However, the difference in Total Services Scores between the no recidivism group ( $\mathrm{M}=1.86, \mathrm{SD}=1.42)$ and the recidivism group $(\mathrm{M}=1.38, \mathrm{SD}=1.32)$ approached significance, with families that did not have a second substantiated abuse case having received more services, $t(118)=1.95, p=.054$.

Chi square tests of independence were conducted between dichotomous variables and maltreatment recidivism. Several significant associations were found. First, children who were temporarily taken from their parents' custody were more likely to a have a second substantiated case $(79 \%$ versus $42 \%), \chi^{2}(1, \mathrm{n}=120)=12.41, p<0.01, p h i=0.32$. Additionally, only $34 \%$ of families with minority caregivers had a case of recidivism compared to $59 \%$ of Caucasian caregivers, $\chi^{2}(1, \mathrm{n}=120)=4.73, p<0.05$, phi $=0.12$. However, there was no significant effect between recidivism and the following variables: domestic violence, alcohol abuse, substance abuse, being a single parent, having a disabled parent, therapy given to the child, therapy given to the caregiver, parenting classes given to parent, anger management given to the parent, substance abuse services given o the parent, or having concrete supports. There was also no association found between any specific type of abuse (physical, sexual, or neglect) and recidivism. Emotional abuse was not examined, as it was only reported in 4 cases. 
Next, a logistic regression was performed to assess the impact of a number of background and intervention variables on the likelihood that a case would have a second substantiated abuse case (i.e., predicting if recidivism would occur). A logistic regression analysis can be used to predict a dichotomous outcome, which in the current study is no recidivism vs. recidivism. Unlike some other types of regression, logistic regression allows for inclusion of scale variables (such as Children's Disability Scale scores) as well as nominal variables (such as whether a family was in a certain treatment group). Thus, a model was created to determine the extent to which substantiated maltreatment recidivism could be predicted based on background and CPS intervention variables. To preserve power, the number of predictor variables was limited to 10 . Based on the literature, research questions focusing on CPS interventions, and investigatory analyses, the five background predictors were selected (minority status of the caregiver [yes/no], index event was for neglect [yes/no], index event was for physical or sexual abuse [yes/no], number of children in the family, and the Children's Disability Scale), and 5 interventions were selected (therapy for the caregiver [yes/no], parenting classes [yes/no], anger management [yes/no], child temporarily removed from the family, and number of concrete supports given). The results table for the regression can be found in Table 2 .

The overall model was found to be significant, $\chi^{2}(5, \mathrm{n}=120)=34.22, p<0.01$, indicating that the model was effective at predicting recidivism. The model as a whole accounted for between 25.0\% (Cox \& Snell R Square) and 33.0\% (Negelkerke R Squared) of the variance in recidivism outcomes. Furthermore, the model correctly predicted $70.0 \%$ of the cases. However, only 3 predictors were found to be significant. Having at least one caregiver who received therapy as part of their intervention reduced 
recidivism by a factor of $0.32(\mathrm{p}<0.05)$, and families with at least one minority parent were less likely to recidivism by a factor of $0.35(\mathrm{p}<0.05)$. The strongest predictor in the model was whether or not the child was temporarily removed from their caregivers' custody. Children who were taken out of their caregivers' custody were 8.91 times more likely to experience a substantiated case of recidivism. Although no other predictors contributed significant variance to the model, several others were approaching significance, and may have been identified were there more cases. In particular, though not statistically significant $(p=0.096)$, having more children in the family was associated with a higher likelihood of recidivism, with each additional child in the family increasing the odds of recidivism by a factor of 1.48 .

Table 2. Logistic Regression Table

\begin{tabular}{|c|c|c|c|c|c|}
\hline PREDICTOR & $\mathrm{B}$ & S.E. B & WALD'S & SIG. & EXP(B) \\
\hline $\begin{array}{l}\text { Therapy for } \\
\text { Parent }\end{array}$ & -1.15 & .55 & 4.31 & .04 & .32 \\
\hline $\begin{array}{l}\text { Parenting } \\
\text { Classes } \\
\end{array}$ & -.23 & .63 & .13 & .71 & .79 \\
\hline $\begin{array}{l}\text { Anger } \\
\text { Management }\end{array}$ & -.35 & .91 & .15 & .70 & .70 \\
\hline $\begin{array}{l}\text { Number of } \\
\text { Con. Supports }\end{array}$ & -.36 & .29 & 1.55 & .21 & .70 \\
\hline $\begin{array}{l}\text { Removed from } \\
\text { Caregiver }\end{array}$ & 2.19 & .61 & 12.90 & $<.001$ & 8.91 \\
\hline $\begin{array}{l}\text { Minority } \\
\text { Parent }\end{array}$ & -1.05 & .51 & 4.18 & .04 & .35 \\
\hline $\begin{array}{l}\text { Children's DB } \\
\text { Score }\end{array}$ & .54 & .36 & 2.30 & .12 & 1.72 \\
\hline $\begin{array}{l}\text { Number of } \\
\text { Children }\end{array}$ & .39 & .24 & 2.77 & .096 & 1.48 \\
\hline Neglect & 1.18 & .90 & 1.74 & .19 & 3.28 \\
\hline $\begin{array}{l}\text { Physical or } \\
\text { Sexual Abuse }\end{array}$ & -.57 & .54 & 1.10 & .29 & .57 \\
\hline
\end{tabular}




\section{DISCUSSION}

With the striking number of negative outcomes associated with child maltreatment, including maladjustment, psychopathology, and delinquency (Bagley \& Mallick, 2000; Fergusson et al., 2008; Schenkel, 2005), prevention of abuse can be considered a top priority. Child Protective Services has been charged with the task of intervening in cases of maltreatment and preventing further abuses from occurring. CPS may take a number of actions to achieve this end, such as providing concrete supports, removing the child from the home, or providing multiple types of therapies for the family. Most research, however, has focused on parent and child factors as predictors of maltreatment recidivism (e.g., Connell et al., 2007; Inkelas \& Halfon, 1997; Jonson-Reid, Drake, Chung, \& Way, 2003), but less is known about the role of CPS intervention in predicting recidivism (Jonson-Reid et al., 2010.). Understanding such predictors may be beneficial in a number of ways. For example, identifying background factors that are associated with an increased risk of recidivism, even those that are unalterable, could inform CPS when more stringent interventions or longer involvement may be needed to prevent recidivism. Moreover, identifying more effective interventions could help CPS develop more effective strategies for dealing with child abuse.

The current study aimed to further examine those findings which were previously inconclusive (e.g., minority status and abuse type), as well as role of CPS interventions given, while taking well-established predictors (e.g., disability status of children and number of children in the family) into account. Thus, archival data was collected from 120 Child Protective Services case files in western North Carolina. 
Findings suggested few significant differences between the recidivism and no recidivism group. Only minority status and temporary placement away from the offending caregiver were found to be significantly related to maltreatment recidivism. Specifically, families with minority parents were less likely to experience recidivism while families in which the children were temporarily removed for the caregivers were more likely to experience recidivism. It is possible that the power of these analyses was limited by small incidences of certain characteristics within the sample, and it is possible that including more cases would have yielded more significant results. For example, an independent samples t-test found cases which did not experience recidivism had received more services, but this difference only approached significance. It is also possible that a third variable (not assessed in this study) would better explain the relationship between minority status and lower recidivism, and between temporary placement and higher likelihood of recidivism.

Next, a logistic regression was used to examine the performance of certain CPS interventions (therapy for the caregiver, parenting classes, anger management, child temporarily removed from the family, and number of concrete supports) given in conjunction with certain background variables (minority status of the caregiver, index event was for neglect, index event was for physical or sexual abuse, number of children in the family, and the Children's Disability Scale) in predicting recidivism. Both minority status of the caregiver and temporary placement away from the caregiver were significantly related to recidivism, as was expected based on exploratory analyses. Additionally, therapy for the caregiver emerged as a significant predictor, with families who received this service being less-likely to experience abuse recidivism. This finding is 
noteworthy because few studies have examined this intervention, and due to the fact that other, well-established predictors, such as having children with disabilities (Connell, et al. 2007), were not found to be significant in the model. A forth predictor, number of children in the family, approached significance. Overall, findings suggest minority parents and parents who have received therapy are less likely to re-abuse their children, while parents who have had their children temporarily taken from their custody are more likely to re-abuse. These findings have practical implications, and add relevant information to the current body of research. Although some studies found that neglect cases have higher recidivism rates (e.g., Hindley et al., 2006), this association was not found in the current study. However, this finding may have been related to the lack of other abuse types in the sample. The finding that minority families are less likely to recidivism their children than white parents is consistent with a few studies in the literature (e.g., Connell, et al., 2007). This finding is interesting, as one would expect that minority individuals would experience more stressors in their lives (e.g., discrimination; Greer \& Chwalisz, 2007), and stress is highly predictive of physical abuse and neglect (Guterman et al., 2009). It is possible that because minority individuals tend to have a lower socioeconomic status (Costello, Keeler, \& Angold, 2001), the types of abuse they are charged with may be less severe neglect charges, although the current study cannot confirm this assumption. Another possible explanation is that some minority groups may experience greater amounts of certain types of social supports (Griffin, Amodeo, Clay, Fassler, \& Ellis, 2006), and social support has been found to be a protective factor against recidivism (DePanfilis \& Zuravin, 1999). 


\section{Inferences}

Although further research is required to confirm the findings of this study, the findings related to CPS interventions may have relevance to CPS practices. First, having a child removed from their caregiver temporarily was by far the strongest predictor of recidivism. This is likely due to the fact that children are usually only removed from their parents in more severe cases. In such cases, more intervention may be required to prevent further abuse. It may also be pertinent for CPS to follow the family for a longer period of time and/or check in on the families more often. On a more positive note, cases in which parents received counseling services had a lower recidivism rate, possibly because counseling could help parents deal with their life stress. Additionally, therapy may also help parents deal with depression and other psychological problems, which some research has found to be linked to maltreatment (Shanahan, 2011). It is understandable that, due to lack of available resources, counseling is not often recommended (occurring in only $25 \%$ of cases in the current study), but our findings suggests it may be helpful for CPS to require more caregivers to attend counseling in appropriate cases.

\section{Limitations}

There are several limitations to the current study that should be considered. First, the data used was archival, and the interventions given by CPS were not under control of the researchers and not randomly assigned. Therefore, there are a number of possible extraneous variables that could have affected outcomes. This, coupled with the inherent complexity of the situations revolving around each unique case, make causality impossible to determine from the current study. Similarly, although the given interventions could be ascertained from the case files, compliance with the ordered 
interventions could not be quantified or controlled for based on the information available. It was also impossible to rule out attrition caused by families moving out of the county. Additionally, the current study relies on substantiated cases; it is possible that further maltreatment was perpetrated and either not reported or lacked sufficient evidence to be proven. A final limitation relates to generalizability; the data set was largely ethnically homogenous, with the vast majority of the sample being Caucasian, albeit representative of the county from which the sample was drawn. Specifically, the U.S. Census Bureau (2012) identifies over 93\% of the population in Haywood County, NC as Caucasian. Furthermore, in some instances the minority status of the subjects was difficult to determine or were labeled in the files in a misleading way, because some social workers label Latino or mixed-raced individuals as white. Because of this, our results may not be applicable to cases involving minorities, and conclusions based on minority status may not be as valid as others. Future studies could address these limitations by using a longitudinal design allowing for a more precise means of following the details of the cases. Additionally, some of the interventions, such as therapy for the caregiver, could possibly be randomly assigned, providing a stronger argument for causality.

Despite the limitations noted above, the present study provided further information about the role of CPS intervention in predicting recidivism, and addressed the need for investigations of recidivism variables that are amenable to change. Furthermore, the results of current study could inform CPS policies in more effective interventions strategies. Such strategies could help to curb the alarming rates of child maltreatment recidivism. 


\section{References}

Asberg, K., \& Renk, K. (in press). Substance use coping as a mediator of the relationship between trauma symptoms and substance use consequences in incarcerated females with childhood sexual abuse histories. Substance Use and Misuse.

Asberg, K., \& Renk, K. (2012). Comparing incarcerated and college student women with histories of childhood sexual abuse: The roles of abuse severity, support, and substance use. Psychological Trauma: Theory, Research, Practice, and Policy. doi: $10.1037 / \mathrm{a} 0027162$

American Academy of Pediatrics. (2001). Children with disabilities are at greater risk for abuse. Pediatrics, 108, 508-513.

Antle, B., Barbee, A., Christensen, D., \& Sullivan, D. (2009). The prevention of child maltreatment recidivism through the Solution-Based Casework model of child welfare practice. Children and Youth Services Review, 31(12), 1346-1351.

Arseneault, L., Cannon, M., Fisher, H. L., Polanczyk, G., Moffitt, T. E., \& Caspi, A. (2011). Childhood trauma and children's emerging psychotic symptoms: A genetically sensitive longitudinal cohort study. The American Journal of Psychiatry, 168(1), 65-72.

Bae, H., Solomon, P., Gelles, R., \& White, T. (2010). Effect of child protective services system factors on child maltreatment rereporting. Child Welfare, 89(4), 33-55.

Bagley, C., \& Mallick, K. (2000). Prediction of sexual, emotional, and physical maltreatment and mental health outcomes in a longitudinal cohort of 290 adolescent women. Child Maltreatment, 5(3), 218-226. 
Baker, A. L., \& Maiorino, E. (2010). Assessments of emotional abuse and neglect with the CTQ: Issues and estimates. Children and Youth Services Review, 32(5), 740748.

Barth, R. P. (2009). Preventing child abuse and neglect with parent training: Evidence and opportunities. The Future of Children, 19(2), 95-118.

Barth, R., Courtney, M., Berrick, J., \& Albert, V. (1994). From child abuse to permanency planning. New York, NY: Aldine De Gruyter.

Barth, R. P., Gibbons, C., \& Guo, S. (2006). Substance abuse treatment and the recurrence of maltreatment among caregivers with children living at home: A propensity score analysis. Journal of Substance Abuse Treatment, 30(2), 93-104.

Bethea, L. (1999). Primary prevention of child abuse. American Family Physician, 59, $1,577-1584$.

Berenbaum, H., Thompson, R. J., Milanak, M. E., Boden, M., \& Bredemeier, K. (2008). Psychological trauma and schizotypal personality disorder. Journal of Abnormal Psychology, 117(3), 502-519.

Berger, L., Paxon, C., \& Waldfogel, J. (2009). Mothers, men, and child protective servce involvement. Child Maltreatment, 14(3), 263-276.

Berger, L., Slack, K., Waldfogel, J., \& Bruch, S. (2010). Caseworker-percieved caregiver substance abuse and child protective service outcomes. Child Maltreatment, 15(3), 199-210.

Bolen, G., McWey, L., \& Schlee, B. (2009). Are at-risk parents getting what they need? Perspectives of parents involved with Child Protective Services. Clinical Social Work Journal, 36, 341-354. 
Block, N. (2003). Disciplinary spanking should be banned. In L. Gerdes (Ed.), Child abuse: Opposing viewpoints (pp. 182-190). New York, NY: Greenhaven Press.

Califano, J. (2003). Substance-abusing parents are more likely to abuse their children. In L. Gerdes (Ed.), Child abuse: Opposing viewpoints (pp. 31-37). New York, NY: Greenhaven Press.

Casanueva, C., Martin, S., Runyan, D., Barth, R., \& Bradley, R. (2008). Parenting services for mothers involved with child protective services: Do they change maternal parenting and spanking behaviors with young children?. Children and Youth Services Review, 30, 861-878.

Caspi, A., McClay, J., Moffitt, T., Mill, J., \& ... Poulton, R. (2002). Role of genotype in the cycle of violence in maltreated children. Science, 297(5582), 851-854.

Chaffin, M., Bonner, B. L., \& Hill, R. F. (2001). Family preservation and family support programs: Child maltreatment outcomes across client risk levels and program types. Child Abuse and Neglect, 25(10), 1269-1289.

Chamberland, C., Laporte, L., Lavergne, C., Tourigny, M., \&Malo, C. (2005).

Psychological maltreatment of children reported to youth protection services: A situation of grave concern. Journal of Emotional Abuse, 5(1), 65-92.

Children's Bureau (2003a). Reducing re-referral in unsubstantiated child protective services cases: Research to practice. Retrieved from http://www.childwelfare.gov/pubs/focus/researchtopractice/researchtopractice.cf m. 
Children's Bureau (2003b). National study of child protective services systems and reform efforts: Review of state cps policy. Washington, DC: U.S. Government Printing Office.

Children's Bureau (2009, February). Definitions of child abuse and neglect: Summary of state laws. Retrieved from http://www.childwelfare.gov/systemwide/ laws_policies/statutes/define.cfm

Conley, A. (2007). Differential response: A critical examination of a secondary prevention model. Children and Youth Services Review, 29(11), 1454-1468.

Connell, C., Bergeron, N., Katz, K., Saunders, L., \& Tebes, J. (2007). Re-referral to Child Protective services: the influence of child, family, and case characteristics on risk status. Child Abuse and Neglect, 31, 573-588.

Connell, C., Vanderploeg, J., Katz, K., Caron, C., Saunders, L., \& Tebes, J. (2009). Maltreatment following reunification: Protective services contact after children return home. Child Abuse and Neglect, 33, 218-228.

Corso, P., \& Fertig, A. (2010). The economic impact of child maltreatment in the United States: Are the estimates credible?. Child Abuse and Neglect, 34, 294-304.

Costello, E. J., Keeler, G. P., \& Angold, A. (2001). Poverty, race/ethnicity, and psychiatric disorder: A study of rural children. American Journal of Public Health, 91, 1494-1498.

Counts, J. M., Buffington, E. S., Chang-Rios, K., Rasmussen, H. N., \& Preacher, K. J. (2010). The development and validation of the protective factors survey: A self report measure of protective factors against child maltreatment. Child Abuse and Neglect, 34(10), 762-772. 
DePanfilis, D., \& Zuravin, S. (1999). Predicting child maltreatment recurrences during treatment. Child Abuse and Neglect, 23(8), 729-743.

Drake, B., Jonson-Reid, M., Way, I., \& Chung, S. (2003). Substantiation and recidivism. Child Maltreatment, 8(4), 248-260.

English, D. J., Marshall, D. B., Brummel, S., \& Orme, M. (1999). Characteristics of repeated referrals to Child Protective Services in Washington State. Child Maltreatment, 4(4), 297-307.

Fassler, I., Amodeo, M., Griffin, M., Clay, C., \& Ellis, M. (2005). Predicting long-term outcomes for women sexually abused in childhood: contribution of abuse severity versus family environment. Child Abuse and Neglect, 29, 269-284.

Fergusson, D., Boden, J., Horwood, L., (2008). Exposure to childhood sexual and physical abuse and adjustment in early adulthood. Child Abuse and Neglect, 32, 607-619.

Fischer, G. J. (1992). Gender differences in college student sexual abuse victims and their offenders. Annals of Sex Research, 5(4), 215-226.

Gratz, K. L., Tull, M. T., Baruch, D. E., Bornovalova, M. A., \& Lejuez, C. W. (2008). Factors associated with co-occurring borderline personality disorder among innercity substance users: The roles of childhood maltreatment, negative affect intensity/reactivity, and emotion dysregulation. Comprehensive Psychiatry, 49(6), 603-615.

Graham, J., English, D., Litrownik, A., Thompson, R., \& Briggs, E., Bangdiwala, S. (2010). Maltreatment chronicity defined with reference to development: 
Extension of the social adaptation outcomes findings to peer relations. Journal of Family Violence, 25, 311-324.

Graham, J., Stepura, K., Baumann, D., \& Kern, H. (2010). Predicting child fatalities among less-severe CPS investigations. Children and Youth Services Review, 32, 274-280.

Greer, T. M., \& Chwalisz, K. (2007). Minority-related stressors and coping processes among African American college students. Journal of College Student Development, 48(4), 388-404.

Griffin, M. L., Amodeo, M., Clay, C., Fassler, I., \& Ellis, M. A. (2006). Racial differences in social support: Kin versus friends. American Journal of Orthopsychiatry, 76(3), 374-380.

Guterman, N. B., Lee, S. J., Taylor, C. A., \& Rathouz, P. J. (2009). Parental perceptions of neighborhood processes, stress, personal control, and risk for physical child abuse and neglect. Child Abuse and Neglect, 33(12), 897-906.

Gil, D. (1995). A sociocultural perspective on physical child abuse. In B. Finkelman (Ed.), Childabuse: A multidiscipanary survey, volume 3: Causes, preventions, and remedies (pp. 7-13). New York, NY: Garland Publishing.

Hicks-Pass, S. (2009). Corporal punishment in America today: Spare the rod, spoil the child? A systematic review of the literature. Best Practices in Mental Health: An International Journal, 5(2), 71-88.

Hindley, N., Ramchandani, P., \& Jones, D. (2006). Risk factors for recurrence of maltreatment: A systematic review. Archives of Disease in Childhood, 91, 744753. 
Hearn, J. (2010). Family preservation in families' ecological systems: Factors that predict out-of-home placement and maltreatment for service recipients in Richmond city. Dissertation Abstracts International Section A, 71, Retrieved from EBSCOhost..

Igarashi, H., Hasui, C., Uji, M., Shono, M., Nagata, T., \& Kitamura, T. (2010). Effects of child abuse history on borderline personality traits, negative life events, and depression: A study among a university student population in Japan. Psychiatry Research, 180(2-3), 120-125.

Inkelas, M., \& Halfon, N. (1997). Recidivism in Child Protective Services. Children and Youth Services Review, 19(3), 139-161.

Jones, L. M., Finkelhor, D., \& Halter, S. (2006). Child Maltreatment Trends in the 1990s: Why Does Neglect Differ From Sexual and Physical Abuse?. Child Maltreatment, 11(2), 107-120.

Jonson-Reid, M., Drake, B., Chung, S., \& Way, I. (2003). Cross-type recidivism among child maltreatment victims and perpetrators. Child Abuse and Neglect, 27(8), 899917.

Jonson-Reid, M., Emery, C. R., Drake, B., \& Stahlschmidt, M. (2010). Understanding chronically reported families. Child Maltreatment, 15(4), 271-281.

Jaffee, S. R., \& Maikovich-Fong, A. (2011). Effects of chronic maltreatment and maltreatment timing on children's behavior and cognitive abilities. Journal of Child Psychology and Psychiatry, 52(2), 184-194.

Jouriles, E., McDonald, R., Rosenfield, D., Norwood, W., Spiller, L., Stephens, N., Corbitt-Shindler, D., Ehrensaft, M. (2010). Improving parenting in families 
referred for child maltreatment: A randomized controlled trial examining effects of Project Support. Journal of Family Psychology, 24(3), 328-338.

Kahn, J., \& Schwalbe, C. (2010). The timing to and risk factors associated with child welfare system recidivism at two decision-making points. Children and Youth Services Review, 32, 1035-1044.

Kaufman, J., \& Zigler, E. (1989). The intergenerational transmission of child abuse. In D. Cicchetti \& V. Carlson (Eds.), Child maltreatment: Theory and research on the causes and consequences of child abuse and neglect (pp. 129-150). New York: Cambridge University Press.

Lemmon, J. H. (2006). The effects of maltreatment recurrence and child welfare services on dimensions of delinquency. Criminal Justice Review, 31(1), 5-32.

Li, F., Godinet, M. T., \& Arnsberger, P. (2011). Protective factors among families with children at risk of maltreatment: Follow up to early school years. Children and Youth Services Review, 33(1), 139-148.

Lobbestael, J., Arntz, A., \& Bernstein, D. P. (2010). Disentangling the relationship between different types of childhood maltreatment and personality disorders. Journal of Personality Disorders, 24(3), 285-295.

Loper, A., Mahmoodzadegan, N., \& Warren, J. I. (2008). Childhood maltreatment and Cluster B personality pathology in female serious offenders. Sexual Abuse: Journal of Research and Treatment, 20(2), 139-160.

McDonald, T., \& Marks, J. (1991). A review of risk factors assessed in Child Protective Services. The Social Service Review, 65(1), 112-132. 
McCarroll, J. E., Fan, Z., Newby, J. H., \& Ursano, R. J. (2008). Trends in US army child maltreatment reports: 1990-2004. Child Abuse Review, 17(2), 108-118.

Messman-Moore, T. L., \& Brown, A. L. (2004). Child maltreatment and perceived family environment as risk factors for adult rape: Is child sexual abuse the most salient experience?. Child Abuse and Neglect, 28(10), 1019-1034.

Mollerstrom, W. W., Patchner, M. A., \& Milner, J. S. (1992). Family functioning and child abuse potential. Journal of Clinical Psychology, 48(4), 445-454.

Mallucio, A., Ainsworth, F., \& Thoburn, J. (2000). Child welfare outcome research in the United States, the United Kingdom, and Australia. Washington, DC: CWLA Press.

National Coalition for Child Protection Reform. (2003). Poverty is the leading cause if child abuse. In L. Gerdes (Ed.), Child abuse: Opposing viewpoints (pp. 26-30). New York, NY: Greenhaven Press.

Nederlof, E. E., Van der Ham, J. M., Dingemans, P. A., \& Oei, T. I. (2010). The relation between dimensions of normal and pathological personality and childhood maltreatment in incarcerated boys. Journal of Personality Disorders, 24(6), 746762.

Noll, J. (2008) Sexual abuse of children - unique in its effects on development?. Child Abuse and Neglect, 32, 603-605.

North Carolina Department of Social Services (2012, March 29). Child welfare central registry statistics. Retrieved from http://www.ncdhhs.gov/dss/stats/cr.htm 
Orr, S. (2003). Family preservation programs put children at risk. In L. Gerdes (Ed.), Child abuse: Opposing viewpoints (pp. 157-170). New York, NY: Greenhaven Press.

Paavilainen, E., \& Åstedt-Kurki, P. (2003). Functioning of child maltreating families: Lack of resources for caring within the family. Scandinavian Journal of Caring Sciences, 17(2), 139-147.

Prior, M. K., \& Quinn, A. S. (2010). The relationship between childhood emotional neglect and adult spirituality: An exploratory study. Journal of Religion and Spirituality in Social Work: Social Thought, 29(4), 277-299.

Rogosch, F. A., \& Cicchetti, D. (2005). Child maltreatment, attention networks, and potential precursors to borderline personality disorder. Development and Psychopathology, 17(4), 1071-1089.

Runyan, D. K., Cox, C. E., Dubowitz, H., Newton, R. R., Upadhyaya, M., Kotch, J. B., \& ... Knight, E. D. (2005). Describing maltreatment: Do child protective service reports and research definitions agree?. Child Abuse and Neglect, 29(5), 461-477.

Shaffer, A., Yates, T. M., \& Egeland, B. R. (2009). The relation of emotional maltreatment to early adolescent competence: Developmental processes in a prospective study. Child Abuse and Neglect, 33(1), 36-44.

Senn, T. E., \& Carey, M. P. (2010). Child maltreatment and women’s adult sexual risk behavior: Childhood sexual abuse as a unique risk factor. Child Maltreatment, 15(4), 324-335.

Schenkel, L. S., Spaulding, W. D., DiLillo, D., \& Silverstein, S. M. (2005). Histories of childhood maltreatment in schizophrenia: Relationships with premorbid 
functioning, symptomatology, and cognitive deficits. Schizophrenia Research, 76(2-3), 273-286.

Semidei, J., Radel, L., \& Nolan, C. (2001). Substance abuse and child welfare: Clear linkages and promising responses. Child Welfare: Journal of Policy, Practice, and Program, 80(2), 109-128.

Slep, A., \& Heyman, R. E. (2006). Creating and field-testing child maltreatment definitions: Improving the reliability of substantiation determinations. Child Maltreatment, 11(3), 217-236.

Southerland, D., Casanueva, C. E., \& Ringeisen, H. (2009). Young adult outcomes and mental health problems among transition age youth investigated for maltreatment during adolescence. Children and Youth Services Review, 31(9), 947-956.

Spinetta, J., \& Riger, D. (1995). The child-abusing parent: A psychological review. In B. Finkelman (Ed.), Childabuse: A multidiscipanary survey, volume 3: Causes, preventions, and remedies (pp. 14-22). New York, NY: Garland Publishing.

Svevo-Cianci, K., Hart, S., \& Rubinson, C. (2010). Protecting children from violence and maltreatment: A qualitative comparative analysis assessing the implementation of U. N. CRC Article 19. Child Abuse and Neglect, 34, 45-56.

Thompson, R., \& Wiley, T. (2009). Predictors of re-referral to child protective services: A longitudinal follow-up of an urban cohort maltreated as infancy. Child Maltreatment, 14(1), 89-99.

Thornberry, T., Henry, K., Ireland, T., \& Smith, C. (2010). The causal impact of childhood limited and adolescent maltreatment on early adult adjustment. Journal of Adolescent Health, 46, 359-365. 
Trent, L., Stander, V., Thomsen, C., \& Merrill, L. (2007). Alcohol abuse among U.S. Navy recruits who were maltreated in childhood. Alcohol and Alcoholism, 42(4), $370-375$.

Ung, T. (2009). Pathways to child maltreatment in families: Exploring social capital, human capital, and functioning. Dissertation Abstracts International Section A, 70

U. S. Department of Health and Human Services, Administration on Children, Youth, and Families (2010). Child maltreatment 2009. Washington DC: U.S. Government Printing Office.

U.S. Census Bureau (2012, January 31). State \& county quickfacts: Haywood County, North Carolina. Retrieved from http://quickfacts.census.gov/qfd/states

Wekerle, C., Leung, E., Wall, A., MacMillan, H., \& Boyle, M., Trocme, N., \& Waechter, R. (2009). The contribution of childhood emotional abuse to teen dating violence among Child Protective Services-involved youth. Child Abuse and Neglect, 33, 45-58.

Wekerle, C., Wall, M., Leung, E., \& Trocme, N. (2007). Cumulative stress and substantiated maltreatment: The importance of caregiver vulnerability and adult partner violence. Child Abuse and Neglect, 31, 427-443.

Wolock, I., \& Magura, S. (1996). Parental substance abuse as a predictor of child maltreatment re-reports. Child Abuse and Neglect, 20(12), 1183-1193.

Wood, J. (1997). Risk predictors for recidivism or re-neglect in a predominantly Hispanic population. Child Abuse and Neglect, 21(4), 379-389. 
Young, N., Gardner, S., \& Dennis, K. (1998) Responding to alcohol and other drug problems in child welfare: weaving together practice and policy. Washington, D.C.: CWLA. 


\section{APPENDIX A: DATA FORM}

ID Number:

Intake Date:

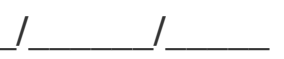

Child Demographics 1:

DOB

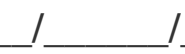

Age:

Sex: 1-Male / 2- Female Mental/Emotional Dis: 0-No / 1 - Yes

Ethnicity: Mark all that apply

Physical Disability 0- No/ 1- Yes

1-Caucasian / 2-Afr.-American / 3- Latino / 4 - Asian / 5 - Nat. American / 5 - Other

Child Demographics 2:

DOB

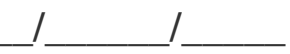

Age:

Sex: 1-Male / 2- Female Mental/Emotional Dis: 0 - No / 1 - Yes

Ethnicity: Mark all that apply

Physical Disability 0- No/ 1- Yes

1-Caucasian / 2-Afr.-American / 3- Latino / 4 - Asian / 5 - Nat. American / 5 - Other

Child Demographics 3:

DOB

Age: ___ Sex: 1-Male / 2- Female Mental/Emotional Dis: 0 - No / 1 - Yes

Ethnicity: Mark all that apply

Physical Disability 0- No/ 1- Yes

1-Caucasian / 2-Afr.-American / 3- Latino / 4 - Asian / 5 - Nat. American / 5 - Other

Caregiver Demographics 1: Maltreating: 0- No / 1 - Yes

DOB

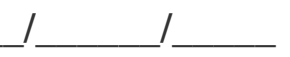

Age at Index: Sex: 1-Male / 2- Female Mental/Emotional Dis: 0 - No / 1 - Yes

Ethnicity: Mark all that apply

Physical Disability 0- No/ 1- Yes

1-Caucasian / 2-Afr.-American / 3- Latino / 4 - Asian / 5 - Nat. American / 5 - Other:

Employment: 0 - Unemployed / 2 - Part Time / 3 - Full Time 
Rel. to Child: 1 - Biological Parent / 2 - Step / 3 - Relative / 4 - Non-Related Caregiver

Caregiver Demographics 2: Maltreating: 0- No / 1 - Yes DOB 1

Age at Index: Sex: 1-Male / 2- Female Mental/Emotional Dis: 0 - No / 1 - Yes

Ethnicity: Mark all that apply Physical Disability 0- No/ 1- Yes

1-Caucasian / 2-Afr.-American / 3- Latino / 4 - Asian / 5 - Nat. American / 5 - Other

Employment: 0 - Unemployed / 2 - Part Time / 3 - Full Time

Rel. to Child: 1 - Biological Parent / 2 -Step / 3 - Relative / 4 - Non-Related Caregiver Other Child or Caregiver Info:

\section{Family/ Situational:}

Alcohol Abuse: 0 - No / 1 - Yes

Substance Abuse: 0 - No / 1 - Yes Substance(s):

Caregiver Rel. Status: 0 - Single / 1 - Married / 2 - Separated / 3 - Divorced / 4 Cohabitating

CPS Interventions given or ordered:

Parenting Classes: 0 - No / 1 - Yes Anger / Stress Management: 0 - No / 1 - Yes

Substance Abuse Services: 0 - No / 1 - Yes Therapy for Parent: 0 - No / 1 - Yes

Therapy for Child: 0 - No / 1 - Yes

Child Placement Outside of the Home: 0 - No / 1 - Yes 
Duration (Months): Times Placement was Changed:

Returned to Caregiver: 0 - No / 1 - Yes

T-1 With Whom: 0 - N/A / 1 - Other Parent / 2 - Other Relative / 3 - Foster Care

T-2 With Whom: 0 - N/A / 1 - Other Parent / 2 - Other Relative / 3 - Foster Care

T-3 With Whom: 0 - N/A / 1 - Other Parent / 2 - Other Relative / 3 - Foster Care

T-4 With Whom: 0 - N/A / 1 - Other Parent / 2 - Other Relative / 3 - Foster Care

Concrete Support: 0 - No / 1 - Yes Number of Concrete Supports:

Description of Concrete Supports:

Abuse types (mark all that apply): Reabuse: (0 - No / 1- yes) Time Since

Intake

Sexual Abuse (0-No / 1 - Yes)

Sexual Abuse (0-No / 1 - Yes)

Physical Abuse (0-No / 1 - Yes)

Physical Abuse (0-No / 1 - Yes)

Emotional Abuse (0-No / 1 - Yes)

Emotional Abuse (0-No / 1 - Yes)

Neglect (0-No / 1 - Yes)

Neglect (0-No / 1 - Yes)

Services needed (0-no/ 1-Yes)

Other Information: 